\title{
Genealogia em Gilles Deleuze e Michel Foucault: \\ por uma ciência nômade
}

Izabel Rizzi Mação ${ }^{1}$

Davis Moreira Alvin²

Resumo: A genealogia opera como uma ciência nômade. Enredada aos princípios do jogo conflito, acaso, simulação e vertigem -, ela se coaduna a saberes ambulantes, que não cessam de seguir os fluxos, as desterritorializações, os modelos hidráulicos e as heterogeneidades. A partir das reverberações da proposta genealógica de Friedrich Nietzsche, elabora-se um encontro entre os pensamentos de Michel Foucault e Gilles Deleuze, autores que reinventam a genealogia nietzschiana. Observam-se suas orientações em direção à produção da genealogia da história, destacando os aspectos nômades ou menores presentes nesse processo interpretativo. Enfim, elucidam-se três aspectos da genealogia, elementares para a análise histórica: a avaliação das origens, a crítica como elemento diferencial da avaliação e a criação de novos valores.

Palavras-chave: genealogia. história. ciência nômade.

I.

História é agôn, é alea, é mimecry e é ilinx.

Ou seja, história é conflito, acaso, simulação e vertigem. Espreitá-la é se colocar num jogo que envolve competição, sorte, artifício e acidente. Durval Muniz de Albuquerque Júnior (2007) assinala ter sido com Friedrich Nietzsche que o jogo passou de um significante para se

\footnotetext{
${ }^{1}$ Mestre em História pela Universidade Federal do Espírito Santo. Doutoranda em História pela Universidade Federal do Espírito Santo - UFES com o apoio da Fundação de Amparo à Pesquisa e Inovação do Espírito Santo (FAPES). Integrante do Grupo de Estudos em Gênero e Sexualidades (GEPSs) e do Núcleo de Estudos e Pesquisas em Sexualidades (NEPS).

${ }^{2}$ Universidade Federal do Espírito Santo. Doutor em Filosofia pela Pontifícia Universidade Católica de São Paulo. Pós-doutorado em Psicologia Institucional pela Universidade Federal do Espírito Santo. Professor de História do Instituto Federal do Espírito Santo. Professor do Programa de Pós-graduação em Ensino de Humanidades (PPGEH - Ifes) e Programa de Pós-graduação em Psicologia (PPGPSi - UFES). Membro do Núcleo de Estudos e Pesquisas em Gênero e Sexualidades (GEPSs/UFES).
}

Vol. 02, N. 02, Abr. - Jun., 2019 - www.revistas.unilab.edu.br/index.php/rebeh 
tornar um paradigma. É com Nietzsche que a relação agonística, representada pelos princípios do jogo, torna-se fundamento epistemológico e ético para a história. Nomear a história segundo os princípios do jogo é, assim, um dos princípios da operação genealógica. E o que o I 5 [ 0

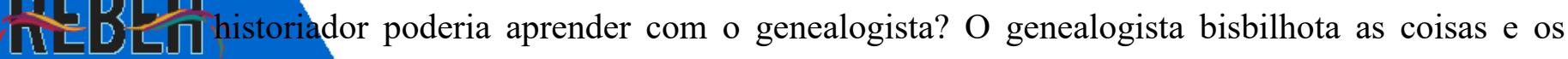
fenômenos para interpretá-los - ou avaliá-los - astuciosamente, sem a fixidez da sabedoria e as armadilhas da contemplação. Ele escuta, cuidadosamente, os barulhos de fabricação histórica. Espanando a poeira acumulada pelo passado e espiando as "origens" das coisas, lá onde alguns historiadores pretendem descobrir a identidade, o genealogista encontra " “[...] algo completamente diferente': não absolutamente seu segredo essencial e sem data, mas o segredo de que elas são sem essência ou que sua essência foi construída peça por peça [...]" (FOUCAULT, 2005, p. 262). Para a pergunta “como essa coisa apareceu?", o genealogista responde: nasceu de "[...] uma maneira racional, como seria justo - pelo acaso [...]" (NIETZSCHE, 2008, § 123).

Gilles Deleuze (2018, p. 11) indica que Nietzsche esperava muitas coisas de sua concepção genealógica: “[...] uma nova organização das ciências, uma nova organização da filosofia, uma determinação dos valores do futuro". Nietzsche reivindica o surgimento de uma nova ciência, uma nova forma de fazer história e, ainda, uma outra maneira de trabalhar com as origens. Neste artigo, propomos um encontro entre os pensamentos de Michel Foucault e Gilles Deleuze a partir de suas reinvenções da genealogia nietzschiana, observando suas sugestões em direção a uma genealogia da história, operada na forma de uma ciência nômade que maneja a história por meio da avaliação dos começos, da crítica como elemento diferencial e da criação de novos valores.

II.

A genealogia é, antes de tudo, uma ciência nômade. Gilles Deleuze e Félix Guattari (1997, p. 41) indicam a existência de um conjunto de saberes nômades, exteriores ao aparelho de Estado, que não estão destinados a tomar o poder, mas, ao contrário, a "[...] seguir o fluxo da matéria, traçar e conectar o espaço liso". São saberes ambulantes que estabelecem sua relação com a terra por meio de um forte coeficiente de desterritorialização, ou seja, ciências menores que seguem modelos hidráulicos e não uma teoria dos sólidos. Direcionam-se, antes, ao devir, à heterogeneidade e às organizações turbilhonares, contrapondo-se às noções de estabilidade, eternidade, identidade, constância e linearidade. De um lado, encontra-se um Vol. 02, N. 02, Abr. - Jun., 2019 - www.revistas.unilab.edu.br/index.php/rebeh 
modelo estatal ou legalista, que insiste em colocar as constantes em evidência e construir equações; de outro, a preocupação em captar singularidades e colocar as variáveis em estado de variação contínua. Esses saberes nômades se manifestam extrinsecamente em relação ao

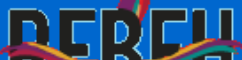
[1]느 L $5 \pi$ aparelho estatal, ainda que não parem de ser barrados, disciplinados, inibidos ou proibidos pelas ciências de Estado. Perante essa linha fugidia, os conhecimentos de Estado agem, preferencialmente, por meio da estratificação, administração e seleção, enquanto as ciências nômades operam linhas de fuga, colocando-se como matéria desestratificada e desterritorializada.

Ciência de Estado e ciência nômade: são dois procedimentos científicos bastante diferentes. O primeiro funciona reproduzindo, o segundo opera seguindo. A ciência de Estado parte de operações dedutivas, indutivas e reprodutivas, tratando "[...] as diferenças de tempo e lugar como tantas outras variáveis das quais a lei extrai precisamente a forma constante" (DELEUZE; GUATTARI, 1997, p. 40). Exercida a partir da constância e da conservação, ela despotencializa as singularidades, sintetizando-as numa matéria uniforme. Isso porque, na ciência de Estado, encontra-se não apenas a regularidade de uma forma de pensamento (reprodução, dedução, indução), mas a própria imagem-Estado, replicada infinitamente em cada coisa ou fenômeno. Esse procedimento tende a indicar a repetição dos fenômenos caso as mesmas condições sejam dadas ou, ainda, caso a mesma relação constante seja estabelecida entre as condições diversas e os fenômenos variáveis.

A ciência régia encontra regularidades por toda parte, submetendo cada circunstância do acaso a centros gravitacionais. Com isso, o pensamento ganha uma gravidade que ele não possui por si só, de modo que as coisas parecem existir por si mesmas, graças a sua sanção ou utilidade próprias. Nesse sentido, é característico das ciências de Estado subordinar as forças imprevisíveis dos fluxos a condutos, canos e diques que controlem as turbulências e imponham um movimento linear, canalizando-os de um ponto a outro. Assim, se, por um lado, a ciência de Estado reconhece a singularidade dos acontecimentos, por outro, ela os endereça a uma órbita exclusiva ou a um campo gravitacional específico. Podemos ver esse processo funcionando na representatividade: uma mulher representa outras mulheres, um cientista outro cientista, um membro de uma classe liga-se aos anseios de sua própria classe e assim por diante. Para cada sujeito histórico distribui-se uma invariável ao redor do qual ele gravita, mas de onde parece ter poucas chances de escapar. Albuquerque Júnior (2007), referindo-se ao livro $O$ queijo e os vermes, de Carlo Ginzburg (2006), sintetiza esse Vol. 02, N. 02, Abr. - Jun., 2019 - www.revistas.unilab.edu.br/index.php/rebeh 
pensamento. Mesmo ao manejar os campos da história do cotidiano, da micro-história ou da chamada história dos excluídos, não se abandonam as operações centralizadoras e Estatais quando, por exemplo, Menocchio, o singular moleiro friulano, torna-se, na visão de Ginzburg, D 5 ए $0,57 \Pi$

[1]느 D $\frac{5}{6}$ " "...] o representante de uma classe, o representante de nosso humanismo meta-histórico

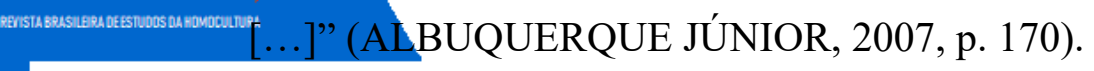

Já uma ciência do tipo nômade segue as singularidades e os desvios, como quem segue sulcos escavados num processo de escoamento da água. Ela instala-se nesse desvio esculpido pelo fluxo da água, tal qual a semente ali se instala, fazendo nascer outra planta e expandindo seu território em um continuum variável. Ao contrário das ciências de Estado - que extraem o invariável do variável -, a ciência nômade coloca as variáveis em variação perpétua, captando ou determinando as singularidades dos fenômenos, em vez de extrair deles uma forma exclusiva. Não “[...] se representa, engendra-se e percorre-se [...]” (DELEUZE; GUATTARI, 1997, p. 30). Isso porque as ciências nômades ultrapassam as possibilidades de formalização e sintetização em um método, procedendo, primeiramente, a partir da criação de problemas. Trata-se da afirmação de uma relação íntima com um "[...] a-mais que transborda ao campo da reprodução, logo se chocam com dificuldades insuperáveis desse ponto de vista, que elas resolvem eventualmente graças a uma operação enérgica" (DELEUZE; GUATTARI, 1997, p. 42). Se a ciência régia é conduzida de forma a reprimir as ciências nômades, isso não ocorre em virtude de seu conteúdo inexato ou imperfeito, mas por estas estabelecerem uma relação diferencial com o campo científico.

Para Deleuze e Guattari (1997, p. 47), a potência de uma ciência nômade reside em sua capacidade para destruir os modelos de pensamento formados a partir da imagem-Estado, sua "[...] imagem $e$ suas cópias, o modelo $e$ suas reproduções, toda possibilidade de subordinar o pensamento a um modelo do Verdadeiro, do Justo ou do Direito [...]”. Essa destruição é própria da genealogia. Ela se habitua à estepe e ao deserto, esse espaço onde nenhum traço separa a terra e o céu; onde “[...] não há distância intermediária, perspectiva, nem contorno, a visibilidade é restrita; e, no entanto, há uma topologia extremamente fina, que não repousa sobre pontos ou objetos, mas sobre hecceidades, sobre conjuntos de correlações" (DELEUZE; GUATTARI, 1997, p. 54). Opera-se, desta forma, com um espaço sonoro antes do espaço visual, ouvindo o barulho dos acontecimentos lá mesmo onde eles são fabricados, em toda sua heterogeneidade e ondulação. Seguindo os fluxos e desvios, acontece

Vol. 02, N. 02, Abr. - Jun., 2019 - www.revistas.unilab.edu.br/index.php/rebeh 
de as origens já não estarem endereçadas à imagem-Estado, mas de conjurarem essa imagem,

recorrendo às linhas de fuga informes e ocasionais.

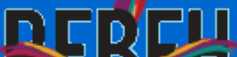
reconstituindo a história de seu projeto filosófico. Na entrevista, Foucault sugere três linhas de estudo possíveis para uma genealogia. Em primeiro lugar, uma ontologia histórica que envolve a relação de nós mesmos com a verdade, nos compondo enquanto sujeitos de conhecimento. Em seguida, uma ontologia de nós mesmos em relação ao poder, nos construindo enquanto sujeitos que agem uns sobre os outros. Enfim, uma ontologia de nossas relações com o campo da moral, "que nos permite constituir-nos como agente éticos" (FOUCAULT, 2014, p. 223). Trata-se, sem dúvida, de um esboço de sua investigação histórica e filosófica. Embora alguns intérpretes das obras de Foucault como, por exemplo, Roberto Machado (1979), reservem o termo "genealogia” para descrever, exclusivamente, as pesquisas que se voltam ao campo do poder, a entrevista acima sugere que a operação genealógica pode ser remetida a todo espectro aberto pelos estudos de Foucault.

Para Foucault (2005, p. 264) o genealogista “[...] tem necessidade da história para conjurar a ilusão da origem, um pouco como o bom filósofo tem necessidade do médico para conjurar a sombra da alma". A genealogia seria, assim, oposta "[...] à pesquisa da 'origem' [...]" (FOUCAULT, 2005, p. 261). Todavia, é preciso analisar essa sentença com alguma cautela, na medida em que a genealogia exige "[...] a minúcia do saber, um grande número de materiais acumulados, paciência [...]. Em suma, uma certa obstinação da erudição [...]" (FOUCAULT, 2005, p. 260). Por que, então, a genealogia nietzschiana se daria num campo oposto ao da pesquisa das origens? Foucault (2005) indica que, nas obras de Nietzsche, o uso do termo Ursprung (origem) aparece alternado ao de Entstehung (emergência) e Herkunft (proveniência). Essas variações possuem sentidos muito diferentes, sugerindo que os objetos de uma genealogia da história passam pela formulação de uma pesquisa das origens oposta, inusitadamente, às "origens".

A análise da proveniência (Herkunft) se opõe às tradicionais pesquisas das origens em, ao menos, três diferentes sentidos. Em primeiro lugar, a proveniência não busca as marcas distintivas de um indivíduo, aquilo que o liga a si mesmo e ao seu próprio povo, definindo o que é grego ou o que é característica de uma classe, por exemplo. Antes, ela trata de descobrir Vol. 02, N. 02, Abr. - Jun., 2019 - www.revistas.unilab.edu.br/index.php/rebeh 
3 as marcas sutis e singulares que podem se entremear em um mesmo indivíduo, compondo una teia difícil de desembaraçar. Segundo Foucault (2005), a noção de proveniência permite ordenar e colocar à parte as marcas diferenciais dos indivíduos e de sua filiação com um povo

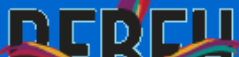
가는 movida pela dessemelhança. Ela opera desenredando forças distintas e classificando seus conjuntos de correlações: forças baixas ou forças altivas que se filiam àquelas de mesma altura ou baixeza.

Em segundo lugar, a proveniência permite "[...] reencontrar, sobre o aspecto único de uma característica ou de um conceito, a proliferação dos acontecimentos através dos quais (graças aos quais, contra os quais) eles se formaram" (FOUCAULT, 2005, p. 264). Lá onde o Eu pretende se unificar em sujeito, se inventar como identidade genuína, o genealogista parte em busca " [...] do começo - dos inúmeros começos [...]; a análise da proveniência permite dissociar o Eu e fazer pulular, nos lugares e recantos de sua síntese vazia, mil acontecimentos agora perdidos [...]" (FOUCAULT, 2005, p. 265). Para Foucault, seguir esse filão complexo da proveniência é manter o que se passou em sua dispersão própria, ordenando os acidentes e os desvios a partir de cálculos complexos entre as forças que fizeram nascer, ao acaso, aquilo que existe e adquiriu valor para nós. Descobre-se, assim, na origem daquilo que conhecemos e do que somos, a exterioridade absoluta do acidente, livre de verdade universal, do sujeito genérico e da imagem-Estado. Trata-se de colocar cada coisa, inclusive o Eu, num estado de variação não-fundacional, que "[...] agita o que antes era imóvel, fragmenta o que se pensava unificado; mostra a heterogeneidade do que se imaginava conforme a si mesmo [...]" (FOUCAULT, 2005, p. 266).

Por fim, a Herkunft liga-se ao corpo, ela se inscreve "[...] no sistema nervoso, no humor, no aparelho digestivo [...]" (FOUCAULT, 2005, p. 266). Para Foucault (2005), o corpo é sustentáculo tanto da sanção da verdade quanto da emergência do acidente. A superfície do corpo suporta e, ao mesmo tempo, suscita um emaranhado de forças que jogam entre si, mediadas, vertiginosamente, pelo acaso. O corpo é lugar de acontecimentos extrínsecos a ele mesmo, na medida em que é uma dimensão de inscrição dos acontecimentos, um campo de dissociação do Eu e uma matéria em perpétua pulverização. Nele, encontra-se o estigma dos acontecimentos passados, os desfalecimentos, os erros e os desejos nascentes. No corpo, as forças se ligam e se exprimem, mas também se desligam, entram em luta ou se apagam. A genealogia é, deste modo, indissociável da articulação entre o corpo e a história, o Vol. 02, N. 02, Abr. - Jun., $2019 \cdot$ www.revistas.unilab.edu.br/index.php/rebeh 
corpo e a verdade, o corpo e as errâncias do acaso. Ela deve mostrar o corpo marcado pela história, “[...] e a história arruinando o corpo [...]” (FOUCAULT, 2005, p. 267).

Já a análise da Etstenhung afasta-se de uma concepção linear da origem na medida em

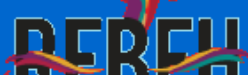

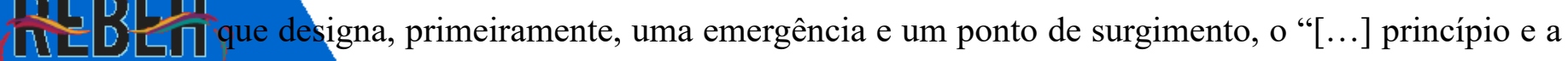

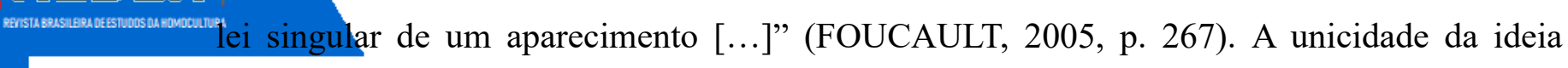
nietzschiana de emergência reside no fato de ela não pretender dar conta de um acontecimento por seus termos finais. Fora de qualquer finalidade monótona, a genealogia da história dedicase a apreciar aquilo que menos se espera, voltando-se para fenômenos que passam por não ter história alguma - como os sentimentos, o amor, a consciência e os instintos. Nesse sentido, ela deserta as ciências de Estado e sua concepção consuetudinária da origem e do processo, centrada na invariabilidade da imagem-Estado e de seus reflexos. Se a ciência régia canaliza a origem para fazê-la ir de um ponto a outro, numa relação causal e evolutiva, a genealogia, enquanto ciência nômade, persegue o desvio lá mesmo onde ele emerge, com suas condições e processos próprios.

Para as ciências de Estado, tudo ocorre como se o olho "[...] tivesse surgido, desde tempos imemoriais, para a contemplação [...]” (FOUCAULT, 2005, p. 267). Ora, quando o genealogista se propõe a estudar a história do olho, deve considerar sua função até mesmo nas criaturas ditas inferiores. Assim, ele instala a análise no declínio (Abkunft) pelo qual o olho humano emergiu como órgão da visão. Observando, por exemplo, o olho dos invertebrados, incapazes de formar imagens, e o sistema de captação de luz da minhoca, presente extensivamente por seu corpo, o genealogista descobre que a contemplação não é o objetivo óbvio do olho. Ela "[...] se manifestou somente quando o acaso constituiu o aparelho da visão [...]" (NIETZSCHE, 2008, § 122). O termo final da visão não passa do episódio atual de uma série de agonismos, já presentes no momento mesmo em que o olho foi submetido à caça e à guerra. É esse processo que a genealogia busca restabelecer, “[...] não absolutamente a potência antecipadora de um sentido, mas o jogo casual das dominações [...]" (FOUCAULT, 2005, p. 268), através do qual o olho tornou-se órgão da visão. Ela encara o começo histórico em toda sua baixeza, pois o começo é sempre “[...] derrisório, irônico, adequado para desfazer quaisquer enfatuações [...]” (FOUCAULT, 2005, p. 263). Não há determinação presente desde o início, nem função orgânica e exclusiva do olho. A emergência do olho como órgão contemplativo só se produziu devido a um certo estado de forças, do jogo e da ação de umas com as outras ou contra si mesmas. Uma análise da emergência Vol. 02, N. 02, Abr. - Jun., $2019 \cdot$ www.revistas.unilab.edu.br/index.php/rebeh 
(Etstenhung), nesse sentido, dedica-se a apreender a entrada em cena das forças, "[...] sua irrupção, o salto pela qual elas passam dos bastidores ao palco [...]” (FOUCAULT, 2005, p. 269)

A genealogia não faz filiação direta, nem representação, mas segue o desvio “[...] até O ponto de sua lacuna, o momento em que eles não ocorreram [...]" (FOUCAULT, 2005, p. 260). Ele aprecia, primeiramente, o jogo da história, sabendo que, no limite, ninguém é responsável por uma emergência, ninguém pode reivindicar a glória por ela. Só há emergência no interstício, na arena onde se passa o jogo. Assim, quando procura pela origem de uma coisa qualquer ou pela verdade sobre um fenômeno, o genealogista percebe só ser possível encontrá-las em “[...] uma invenção (Erfindung), em um passe de mágica, em um artifício (Kunststück), em um segredo de fabricação, em um procedimento de magia [...]" (FOUCAULT, 2005, p. 261). O olhar genealógico não está no nível da natureza como origem, que explica a função do olho por si só, mas no barulho de fabricação da verdade "por trás" do olho. Se o olho aparece, quase exclusivamente, como órgão de ver e contemplar, isso se deve ao longo procedimento de cocção da história pelo qual passou essa verdade e, igualmente, por seu efeito no próprio corpo. Mas essa verdade - o olho serve para contemplar - " [...] e seu reino originário tiveram sua história na história [...]” (FOUCAULT, 2005, p. 264). Para Nietzsche $(2008, \S 122)$, bastaria um “[...] único desses exemplos [...]" para que as causas finais nos caiam dos olhos “[...] como escamas!”.

Para Foucault (2005), o que a genealogia restitui aos fenômenos é sua alocação no labirinto místico do acaso, onde nenhuma verdade os mantinha sob proteção. Nesse processo, ela inverte a relação entre origens e causas finais. No começo das coisas e nas articulações do Eu, não se encontra um fim já programado pela imperatividade do processo, mas a discórdia e o disparate, livres de quaisquer identidades preservadas. A genealogia permite rir das solenidades das origens sem, todavia, livrar-se da potência dos começos, pois é nas síncopes e agitações dos começos que as forças entram ou saem de cena. Na emergência, muda-se o placar do jogo e inverte-se a relação de forças. Trata-se, para a análise da Etstenhung, de ordenar as forças dispostas segundo uma intuição nômade e, ao mesmo tempo, de fazer a emergência pulular em seu caráter único e agudo.

Nos acontecimentos há sempre um irremediável conflito. Para Foucault (2005), o jogo estabelecido entre forças e sentidos, responsáveis por uma emergência, dá-se pela distribuição de uns diante dos outros e uns acima dos outros, num espaço que se divide e se abre entre Vol. 02, N. 02, Abr. - Jun., 2019 - www.revistas.unilab.edu.br/index.php/rebeh 
eles, na arena onde forças fortes e forças fracas disputam entre si. Esse conflito acontece num "não lugar", num campo de "pura distância", porque os jogadores não podem entrar em cena a partir de um plano de igualdade e, também, porque “[...] os adversários não pertencem ao

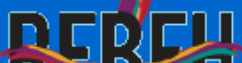
[1]는 $\frac{1}{6}$ ] mesmo espaço [...]" (FOUCAULT, 2005, p. 269). Como sugere Deleuze (2018), as forças que

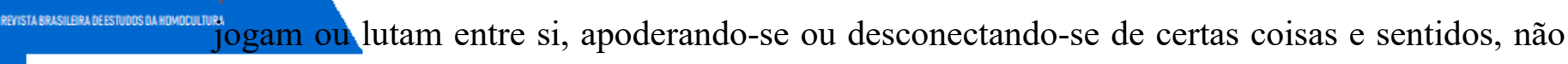
são dotadas da mesma natureza. Há, entre elas, diferenças de valor. Pesar os valores e avaliálos criticamente, partindo de um sentimento de distância, é a tarefa genealógica e criativa por excelência. "Eis por que, sem dúvida, qualquer origem da moral, a partir do momento em que ela não é venerável - e a Herkunft nunca o é -, é crítica" (FOUCAULT, 2005, p. 266).

\section{IV.}

Deleuze (2018) sugere que o projeto mais geral de Nietzsche passa pela introdução dos conceitos de sentido e de valor. Nietzsche nunca escondeu que essa filosofia dos sentidos e dos valores deveria ser forjada como crítica. A “[...] filosofia dos valores, tal como ele a instaura e a concebe, é a verdadeira realização da crítica, a única maneira de realizar a crítica total, isto é, de filosofar 'com o martelo"” (DELEUZE, 2018, p. 9). Uma filosofia dos valores implica dois movimentos distintos e, ao mesmo tempo, inseparáveis. Por um lado, é preciso apreender os valores como princípios dotados de determinado caráter originário, que decide sua origem e seu próprio valor - o valor dos valores. Uma genealogia, desse modo, implica uma avaliação da origem dos valores, remetendo-os àquilo que eles afirmam em seu aspecto essencial. A avaliação do aspecto essencial dos valores, por sua vez, também se relaciona a determinados valores. Isso porque a avaliação contém, em si mesma, perspectivas de mundo, modos de ver, maneiras de ser endereçadas aos seus elementos originários. Isso significa que uma avaliação não é neutra ou imparcial, mas pressupõe valores a partir dos quais aprecia os fenômenos. Por outro lado, e mais profundamente, os valores supõem avaliações, pontos de vista de apreciação de onde deriva seu próprio valor.

Avaliar - ou mesmo interpretar - é pesar delicadamente esses elementos: o essencial dos valores e o elemento diferencial presente na avaliação. Assim, insinua-se a principal questão colocada por uma genealogia, o seu problema crítico: o valor dos valores, a avaliação de onde o próprio valor precede, o problema, por conseguinte, da sua criação. A avaliação é o elemento diferencial dos valores correspondentes, o elemento crítico e, ao mesmo tempo, criador. Quer dizer, a análise genealógica não apenas avalia os valores, remetendo-os a seu Vol. 02, N. 02, Abr. - Jun., 2019 - www.revistas.unilab.edu.br/index.php/rebeh 
caráter essencial. Nesse processo de avaliar, ela também se responsabiliza por criar valores.

Decorre daí que a avaliação e os valores sejam intimamente relacionados ao seu elemento diferencial: às maneiras de ser, aos modos de existência daqueles que julgam e avaliam e, no

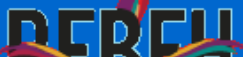

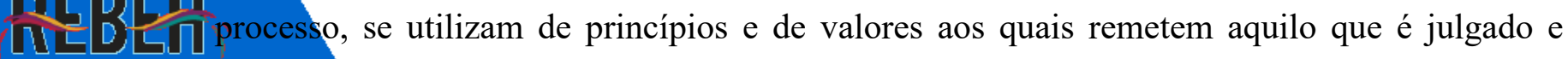

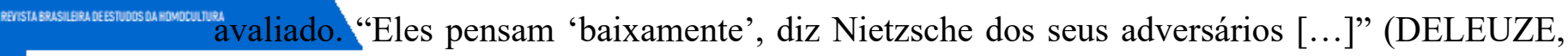
2018, p. 11), pois há forças que não podem entrar em cena sem darem um sentido negativo e um valor restritivo para as coisas e fenômenos, sem propor a baixeza como sentido e modo de vida. É esse o maior medo de Zaratustra, o profeta nietzschiano: confundir-se com seu macaco e, portanto, com a vingança mascarada como elogio da loucura.

A partir do princípio de distância, ou seja, do elemento diferencial, "[...] Nietzsche substitui o princípio da universalidade kantiana, bem como o princípio da semelhança, caro aos utilitaristas, pelo sentimento de diferença ou de distância” (DELEUZE, 2018, p. 10). Essa é a insurgência criativa de Nietzsche em relação aos operários da filosofia e aos utilitaristas. É a partir do elemento diferencial da avaliação que se arroga o direito de criar valores e de manejar a genealogia como crítica absoluta dos valores. Enquanto os operários da filosofia contentam-se em subtrair os valores à crítica, inventariando os valores existentes ou criticando as coisas em nome de valores já estabelecidos; os utilitaristas criticam ou respeitam os valores, tratando-os como derivados de fatos objetivos. A indiferenciação do operacionismo e a universalização utilitária tendem a compreender os valores como sendo insensíveis a sua origem, encerrando-os numa derivação causal de pretensos fatos objetivos, nos quais residiria a origem indiferente e universal dos valores. São ciências régias que não cessam de reproduzir a gravidade do Estado em sua tagarelice sobre a utilidade essencial dos valores atuais. Contra a indiferenciação e a universalização da imagem-Estado, a genealogia trava uma luta dupla.

\footnotetext{
Nietzsche se insurge ao mesmo tempo contra a elevada ideia de fundamento, que deixa os valores indiferentes à sua própria origem, e contra a ideia de uma simples derivação causal ou de um raso começo que coloca uma origem indiferente aos valores. Nietzsche forma o conceito novo de genealogia. O filósofo é o genealogista, não um juiz de tribunal à maneira de Kant, nem um mecânico à maneira utilitarista (DELEUZE, 2018, p. 10).
}

Nietzsche apresenta ao pensamento filosófico o sentimento de diferença ou de distância, isto é, o elemento diferencial e a crítica genealógica, pois nem os valores nem as avaliações são indiferentes às diferenças na origem. Essa origem diferencial está endereçada a certos princípios, nobres ou vis, elevados ou baixos. Eis aqui o essencial: o "[...] elevado e o Vol. 02, N. 02, Abr. - Jun., 2019 - www.revistas.unilab.edu.br/index.php/rebeh 
baixo, o nobre e o vil não são valores, mas representam o elemento diferencial donde deriva o próprio valor dos valores” (DELEUZE, 2018, p. 10). Dessa maneira, a genealogia opera pela delicada pesagem dos elementos diferenciais presentes nos valores e nas avaliações que deles

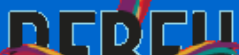
[는 5 L 5 fazemos, se eles estão ligados a forças elevadas ou baixas, se propõem a elevação da vida ou a

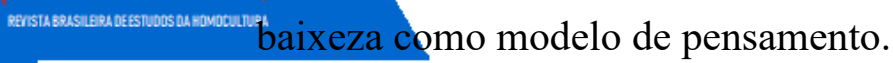

Genealogia quer dizer ao mesmo tempo valor da origem e origem dos valores. Genealogia se opõe ao caráter absoluto dos valores, tanto quanto ao seu caráter relativo ou utilitário. Genealogia significa o elemento diferencial dos valores do qual decorre seu próprio valor. Genealogia quer dizer, portanto, origem ou nascimento, mas também diferença ou distância na origem. Genealogia quer dizer nobreza e baixeza, nobreza e vilania, nobreza e decadência na origem [...] (DELEUZE, p. 1011).

É por haver diferença ou distância na origem que Zaratustra não se confunde com seu macaco: eles não pertencem à mesma espécie, na medida em que são possuídos por valores com uma diferença de natureza entre si.

\footnotetext{
Chamam-te meu macaco, doido raivoso; mas eu chamo-te suíno grunhidor; com teu grunhido acabas por emporcalhar o elogio que eu fiz da loucura. Que te fez grunhir? É porque não te adularam suficientemente; por isso te sentaste ao lado dessas imundícies, a fim de teres numerosas razões de vingança. A vingança, louco raivoso, é a tua espuma (NIETZSCHE, 2007, p. 236).
}

A crítica genealógica, portanto, não pode ser confundida com a vingança, o rancor ou o ressentimento, pois sua natureza é outra. A crítica é, antes, a "[...] expressão ativa de um modo de vida criativo: o ataque, e não a vingança [...]" (DELEUZE, 2018, p. 11). Isso ocorre porque o elevado e o baixo, o nobre e o vil não são valores, mas o elemento diferencial que determina as origens de um valor; são, em suma, pontos de vista a partir dos quais se aprecia um fenômeno ou ordenam-se as origens de um valor. Em uma palavra, o elemento diferencial remete ao modo de ser ou de ver quem julga e avalia, à natureza dos valores movidos nesse processo, as forças que são chamadas para a arena. Para Deleuze (2018, p. 10), é justamente por isso que "[...] temos sempre as crenças, os sentimentos, os pensamentos que merecemos em função da nossa maneira de ser ou do nosso estilo de vida". Afinal, existem coisas que só podem ser ditas, concebidas ou mesmo sentidas quando se relacionam com valores nos quais só se pode acreditar sob a condição de se avaliar vilmente, de viver e pensar com baixeza.

Se genealogia quer dizer diferença na origem há, decerto, decadência na origem de alguns valores e de algumas avaliações, mas há, igualmente, avaliações ou valores que podem Vol. 02, N. 02, Abr. - Jun., 2019 - www.revistas.unilab.edu.br/index.php/rebeh 
ser essencialmente altos e nobres. Trata-se, assim, de referir todas as coisas, bem como todas

as origens, a valores (avaliar); e, ao mesmo tempo, referir esses valores a qualquer coisa como sua brigem e que estipule o seu valor (o elemento diferencial, o alto e o baixo, o nobre e o

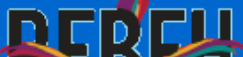
[는ㄷㄴ 5 vil). Para Deleuze (2018), é assim que Nietzsche concebe a crítica: não como mera reação aos valores estabelecidos, mas como elemento afirmativo. Isso porque uma crítica total do valor dos valores não se faz completa se for incapaz de criar valores e novos sentidos de mundo. A crítica não é a reação do ressentimento, a espuma do raivoso, mas a expressão de um modo de vida ativo que, partindo do sentimento de distância, se arroga ao direito de criar valores ou de os determinar. Ela é, portanto, uma ação e exprime o desejo de um modo de fazer e de pensar que se coloca de maneira ativa e criativa no mundo. $\mathrm{O}$ " [...] elemento diferencial não é crítico do valor dos valores, sem ser também o elemento positivo de uma criação [...]" (DELEUZE, 2018 , p. 11). Esse modo de vida ativo conecta-se a um pensamento do tipo nômade, que “[...] se propõe precisamente a manejar o elemento diferencial como crítico e criador, portanto, como um martelo" (DELEUZE, 2018, p. 11). Ele destrói os valores e, também, os reflexos produzidos por suas imagens, reivindicando uma nova ciência, uma nova constelação de sentidos e um outro tempo do jogo entre as forças.

Daí a importância adquirida pela relação entre a essência, o sentido e o jogo das forças na genealogia nietzschiana. "A dualidade metafísica da aparência e da essência e também a relação científica do efeito e da causa são substituídas por Nietzsche pela correlação entre fenômeno e sentido" (DELEUZE, 2018, p. 12). Para Deleuze (2018), uma força é sempre apropriação, exploração e dominação de uma determinada quantidade de realidade, e a história de uma coisa ou fenômeno deve ser concebida como a sucessão entre as forças que deles se apoderaram, em ampla coexistência com as forças que agora lutam para dominá-los. Analisar uma emergência passa pela concepção de que, da arena de onde ela irrompe, “[...] há sempre uma pluralidade de sentidos, uma constelação, um complexo de sucessões, mas também de coexistências, que faz da interpretação uma arte" (DELEUZE, 2018, p. 12). É por isso que, para Deleuze (2018, p. 11), nunca encontramos “[...] o sentido de alguma coisa (fenômeno humano, biológico ou mesmo físico), se não conhecermos qual é a força que se apropria da coisa, que a explora, que dela se apodera ou nela se expressa [...]", pois um mesmo objeto, palavra ou fenômeno muda de sentido de acordo com a força com a qual ele harmoniza.

Vol. 02, N. 02, Abr. - Jun., 2019 - www.revistas.unilab.edu.br/index.php/rebeh 
Não existe acontecimento, objeto ou palavra cujo sentido não seja múltiplo, sendo ora isto, ora aquilo, de acordo com as forças que são chamadas para a cena ou que pulam para a arena. "Eis porque Nietzsche não acredita nos 'grandes acontecimentos' ruidosos, mas na não significa, contudo, abandonar a primazia do elemento diferencial, já que coisa alguma é neutra. Se cada força se apropria de uma quantidade de realidade, cada objeto é responsável por estabelecer uma relação de maior ou de menor afinidade com a força em harmonia com ele atualmente. Aqui, a noção de essência ganha uma nova significação, na medida em que “[...] nem todos os sentidos se equivalem [...]" (DELEUZE, 2018, p. 13). A essência - ou a origem genealógica - é, dentre todos os sentidos possíveis de uma mesma coisa, aquele que lhe dá a força em maior afinidade com ela. Interpretar é captar essa diferença essencial que reside em cada coisa, a diferença na natureza das forças em cena, balanceando o elemento diferencial nelas expresso. O essencial, e o alvo da interpretação genealógica, é, portanto, o elevado e o baixo, o que há de altivo ou decadente em uma determinada coisa e os termos em que são mediados o conflito entre as forças em luta para dela se apoderar.

E é preciso, conforme a percepção de Davis Moreira Alvim e Alexsandro Rodrigues (2016), que estes termos fiquem bem entendidos, para evitar contrassensos. Apoderar-se quer dizer ser capaz de criar ou de impor formas, assenhorar-se é forjar uma outra interpretação. Nesse processo, as forças altivas são aquelas que afirmam sua própria diferença, fazendo dela gozo e alegria, enquanto as forças baixas ou vis, por sua vez, funcionam limitando, separando ou restringindo. As forças altivas são, portanto, forças ativas de transformação, de caráter plástico e inventivo. Já as forças baixas estão ligadas à reação e à administração.

Ao perguntar pela natureza da força, procura-se descobrir se ela expressa um sentido altivo ou decadente, se é nobre ou vil. Avalia-se, assim, a natureza da força. Essa avaliação, contudo, não é imparcial; ao contrário, ela é permeada por valores e visões de mundo. Uma avaliação também pode ser elevada ou baixa, dependendo dos valores nela implicados, de seu elemento diferencial. Em relação à conexão entre a força e o sentido, busca-se estabelecer, dentre todos os sentidos presentes, qual está em maior afinidade com a força que se apodera da coisa naquele momento (sua essência) e, ainda, o conjunto de forças em jogo. A história emerge, para a genealogia, como a sucessão de sentidos de uma mesma coisa ou fenômeno, de acordo com as forças em harmonia com eles e segundo as forças em luta para deles se apoderarem.

Vol. 02, N. 02, Abr. - Jun., 2019 - www.revistas.unilab.edu.br/index.php/rebeh 
Ciência nômade, forjada no jogo de onde irrompe a história e no elemento diferencial,

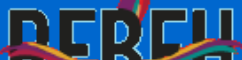
genealógiças precisamos recorrer à distinção feita por Bruno Latour (2019) entre os objetos sem risco e os quase-objetos de risco. As ciências de Estado desdobram-se em objetos com contornos nítidos, essências definidas e propriedades bem reconhecidas. Radicalmente separados do pesquisador, seus objetos pertencem ao mundo das coisas estáveis, definidas por leis de causalidade e noções rígidas de verdade. Os objetos sem risco podem acarretar, sem dúvida, consequências inesperadas. Segundo Latour (2019) tais decorrências, contudo, são sempre pensadas a partir de sua entrada em um universo diferente daquele no qual foram produzidas. Na concepção régia, os desvios, as emergências e os acontecimentos devem, sempre, retornar às linhas de continuidade, pois suas irrupções não podem, jamais, repercutir sobre a definição primeira do objeto, sobre seus contornos e sobre sua essência. Dito de outro modo, os impactos e desvios não devem retroagir sobre a identidade ou propriedade de um objeto, na medida em que isso perturbaria, sobremaneira, a colocação das variáveis em um campo de regularidades.

Os quase-objetos de risco, por sua vez, são completamente diferentes. Eles “[...] não têm contornos nítidos, essências bem definidas, nada de separação traçada entre um núcleo duro e seu entorno [...]" (LATOUR, 2019, p. 46). Seus produtores não são invisíveis, mas controvertidos, complicados e, finalmente, implicados nos problemas que levantam. Não se fala mais no impacto dos objetos de pesquisa, mas de conexões, tentáculos e pseudópodes que os ligam a seres pouco seguros de sua identidade. Como ciência dos quase-objetos de risco, a genealogia abre mão do controle sobre as consequências inesperadas do acaso, e toda pesquisa se volta, precisamente, para os movimentos turbilhonares, singulares ou desviantes, cujas consequências são objetos de responsabilidade e aprendizagem. Parece que, entre os objetos sem risco, característicos da ciência de Estado, e os quase-objetos de risco, tão caros à ciência nômade e à genealogia, um enorme deslocamento se opera. Isso se deve ao fato de os quase-objetos ameaçarem perturbar os ordenamentos reprodutores em sua incessante replicação dos princípios da semelhança e da regularidade.

Contra e para além dos objetos sem risco, das regularidades sistemáticas e lineares das ciências de Estado, a genealogia efetua movimentos de risco, fuga, instabilidade e criação Vol. 02, N. 02, Abr. - Jun., 2019 -www.revistas.unilab.edu.br/index.php/rebeh 
específicos das ciências nômades. Com seus quase-objetos de risco, a genealogia da história torna-se um saber perspectivo, no qual as narrativas de um dado acontecimento incluem a participação do historiador. Contudo, não basta a mera implicação. Enquanto análise da

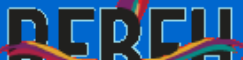

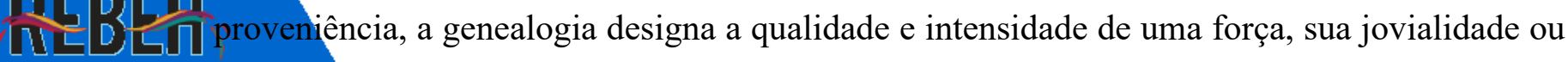
cansaço, bem como as marcas deixadas por ela no corpo. Tal procedimento encontra múltiplos lugares de confrontação e emergência, ou seja, momentos nos quais as forças entraram em cena para tomar o palco ou perecer. São operações avaliativas que se conectam a uma ação crítica, balanceada pelo elemento diferencial. Não se trata apenas de inventariar os valores baixos do mundo, é preciso destruí-los e manejar a crítica como um martelo ou uma faca. $\mathrm{O}$ saber, nesse sentido, deve operar como uma lâmina, pois não foi feito para compreender ou restituir - a nossa identidade, o nosso Eu, o nosso passado - e sim para cortar. Ou, então, todo o trabalho em direção à produção da história como totalidade, tudo o que permite traçá-la como movimento linear e marcá-la como uma continuidade, "[...] trata-se sistematicamente de destruir tudo isso" (FOUCAULT, 2005, p. 272).

Se o mundo "[...] nos parece hoje "maravilhosamente matizado, profundo, pleno de sentido' é porque uma 'multidão de erros e fantasmas' o fez nascer e o povoa [...]", mesmo que ainda em segredo (FOUCAULT, 2005, p. 273). A genealogia segue por linhas informes do acaso, linhas erráticas ou fantasmáticas, pesando delicadamente as forças em jogo. E ocorre de o acaso não ser simples sorteio, mas uma ligação arriscada com a vontade da força. Para cada aparecimento do acaso, há, como forma de controlá-lo, o risco de um acaso ainda maior, de uma entrada em cena de forças ainda mais violentas. $\mathrm{O}$ genealogista toma o mundo como essa miríade, formada por um amontoado de acontecimentos, em que forças se ligam ou se desligam numa luta perpétua e inventiva. Ele é, conforme a sugestão de Deleuze e Guattari (1997), um beduíno, um andarilho dos desertos gelados ou arenosos. Em sua caminhada, a localidade se metamorfoseia em não-lugar e ele perde de perspectiva a divisão entre passado, presente e futuro. No horizonte indefinido do deserto de onde se faz a análise, borram-se as fronteiras do próprio tempo, esse inevitável companheiro da humanidade, e o isto e depois aquilo já não acontecem segundo uma temporalidade linear, mas a partir do tecido muito mais complexo do jogo.

Para Nietzsche $(2008, \S 49)$, com a gênese cristã, a humanidade buscava despertar o sentimento de soberania mostrando sua origem divina, porém, no início da humanidade está o símio e, no final do caminho que ela tomou para provar sua soberania, está “[...] a urna Vol. 02, N. 02, Abr. - Jun., 2019 - www.revistas.unilab.edu.br/index.php/rebeh 
funerária do último homem que enterra os mortos". Por outro lado, com a genealogia, não se

vai do símio ao último homem ou do estado de natureza ao sujeito universal. Antes, segue-se o conjunto de correlações que fizeram de nós sujeitos do conhecimento, dotados de um Eu

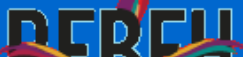

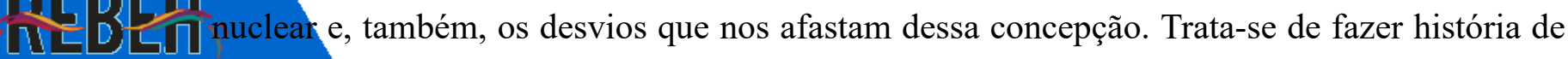
uma maneira estranha e torná-la, de fato, amiga do conhecimento, pois o amigo, diz Zaratustra, é sempre um terceiro entre eu e mim, “[...] que me leva a me superar e ser superado" (DELEUZE, 2018, p. 14). Eis aqui o essencial: superar o sujeito e partir em direção às multidões extemporâneas, ligando-se a sua solidão absoluta. E essa solidão é extremamente povoada, "[...] como o próprio deserto, uma solidão que já se enlaça a um povo por vir, que invoca e espera esse povo, que só existe graças a ele, mesmo se ele ainda falta..." (DELEUZE; GUATTARI, 1997, p. 46).

\section{REFERÊNCIAS}

ALBUQUERQUE JÚNIOR, Durval Muniz de. A história em jogo: a atuação de Michel Foucault no campo da historiografia. In: História: a arte de inventar o passado. Ensaios de teoria da história. São Paulo: Edusc, 2007. p. 165-182.

DAVIS, Moreira Alvim; RODRIGUES, Alexsandro. Como cartografar resistências? Apontamentos sobre contradispositivo e criação. Revista Lugar Comum, Rio de Janeiro, n. 48, v. 2, p. 103-119, jun./ago. 2016.

DELEUZE, Gilles. Nietzsche e a filosofia. São Paulo: n-1, 2018.

DELEUZE, Gilles; GUATTARI, Félix. Mil Platôs: capitalismo e esquizofrenia, vol. 5. São Paulo: Ed. 34, 1997.

FOUCAULT, Michel. Nietzsche, a genealogia, a história. In: Ditos \& Escritos II: arqueologia das ciências e história dos sistemas de pensamento. Rio de Janeiro: Forense Universitária, 2005. p. 260-281.

FOUCAULT, Michel. Sobre a genealogia da ética: um resumo do trabalho em curso. In: Ditos e escritos, volume IX: genealogia da ética, subjetividade e sexualidade. Rio de Janeiro: Forense Universitária, 2014. p. 214-237.

GINZBURG, Carlo. O queijo e os vermes. São Paulo: Companhia das Letras, 2006.

LATOUR, Bruno. Políticas da natureza: como associar as ciências à democracia. São Paulo: Editora Unesp, 2019.

MACHADO, Roberto. Por uma genealogia do poder. In: FOUCAULT, Michel. Microfisica do Poder. Rio de Janeiro: Edições Graal, 1979. p. VIII-XXIII.

Vol. 02, N. 02, Abr. - Jun., 2019 ·www.revistas.unilab.edu.br/index.php/rebeh 


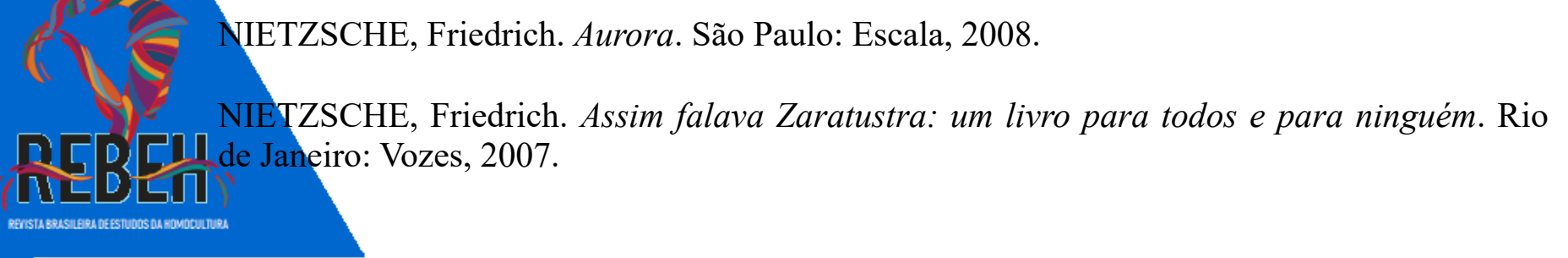

Genealogy in Gilles Deleuze and Michel Foucault: for a nomadic science

\begin{abstract}
Operating as a nomadic science and entangled in the principles of the game conflict, chance, simulation and vertigo -, genealogy pairs with itinerant knowledge, which never cease to follow certain streams, deterritorialization, hydraulic models, and heterogeneities. Following the reverberations of Friedrich Nietzsche's genealogical proposal, I bring together the thoughts of Michel Foucault and Gilles Deleuze, authors who reinvent the Nietzschean genealogy. By highlighting the nomadic or minor aspects present in their interpretative process, I show their orientation towards the production of the genealogy of history. Ultimately, three aspects of genealogy, which are elementary for historical analysis, are elucidated: the evaluation of origins, criticism as a differential element of evaluation, and the creation of new values
\end{abstract}

Keywords: genealogy. history. nomadic science.

Recebido em: 09/10/2019

Aceito em: 10/12/2019

Vol. 02, N. 02, Abr. - Jun., 2019 - www.revistas.unilab.edu.br/index.php/rebeh 